\title{
Analysis of Damaged Concrete Columns of Circular Cross-Section
}

\author{
Matija OREŠKOVIĆ, levgenii KLYMENKO, Aleksej ANISKIN, Goran KOZINA
}

\begin{abstract}
The article shows the development of analytical method for the calculation of damaged reinforced concrete columns of circular cross-section. The theory and the basic settings for the calculation are based on European Eurocode standards. The paper describes the development of method, from basic assumptions (most important assumption arises in condition of the external and internal forces plain parallelism) to the final setting of five equations with five unknowns for further solving using NewtonRaphson method. The final results (via the input and resolved parameters) are given in the height of the compressed area $x$, the stresses in the reinforcement bars $\sigma_{\text {si }}$ and finally, in the current bearing capacity of damaged rc section $N$.
\end{abstract}

Keywords: axial force; bearing capacity; circular column; damage; strain; stress

\section{INTRODUCTION}

Bresler [1] carried out pioneering studies and developed an equation to provide simple, direct and reasonably approximation of strength of a rc column subjected to axial compression and biaxial bending. Later, based on simplifying assumptions, Fekete [2] developed procedures for design graphs of circular columns under axial compression/tension and moment. The Portland Cement Association [3], the Concrete Reinforcing Steel Institute [4] and the American Concrete Institute [5] published tables and charts for the analysis and design of rc circular columns under combined bending and axial compression.

However, since the cross section is circular and by analyzing the damage of part of area, the reinforcement is located at discrete points along the periphery of a circle, the equations of equilibrium are complex and no explicit solutions can be determined.

Basic and detailed research about technical condition of buildings and structures, recommendations for diagnostic are given in the works of Klimenko EV [6 11], MV Zavoloka [11] Matveev EP and Meshechkina VV [12] and others. They discussed certain issues of a technical condition assessment and the impact of various factors on building condition. Klimenko EV emphasizes that the current work on the identification and prediction of technical condition of constructions and structures is carried out on an intuitive level. Disadvantage of such a method of inspection may be that of a subjective judgment and under-estimated strength characteristics of structures. An approach is proposed to determination of technical condition which is based on the prediction of changes in the geometric characteristics and the characteristics of strength of materials. This system makes it possible to formalize the inspection of buildings and structures. The paper also describes the principles of strengthening structures and corrosion protection.

\section{BASIC ASSUMPTIONS FOR CALCULATION}

Existing EU and UA standards for Design of concrete construction, Eurocode 2 [13], DBN B.2.6.-2011 [14] in general used to determine the bearing capacity, displacement, redistribution of forces in statically indeterminate structures, offers to determine the stress- strain state of reinforced concrete cross-sections on the basis of non-linear "stress-strain" diagram shown in Fig. 1 which is described by Eqs. (1) or (2).

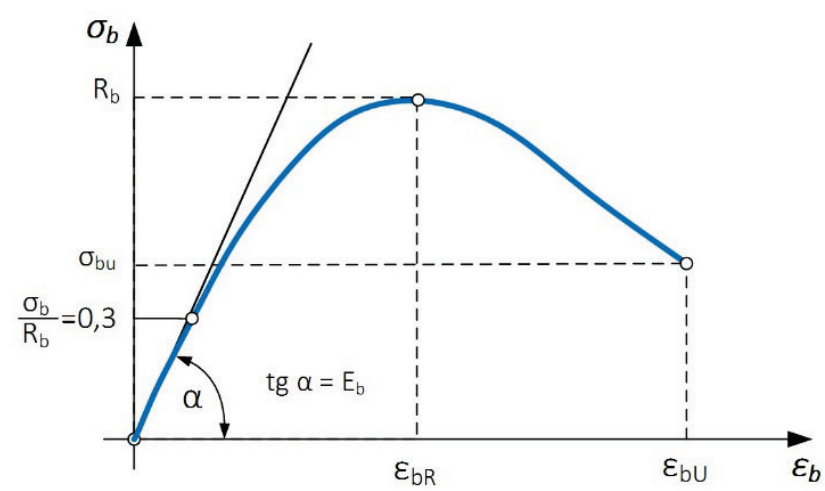

Figure 1 "Stress-strain" diagram of concrete

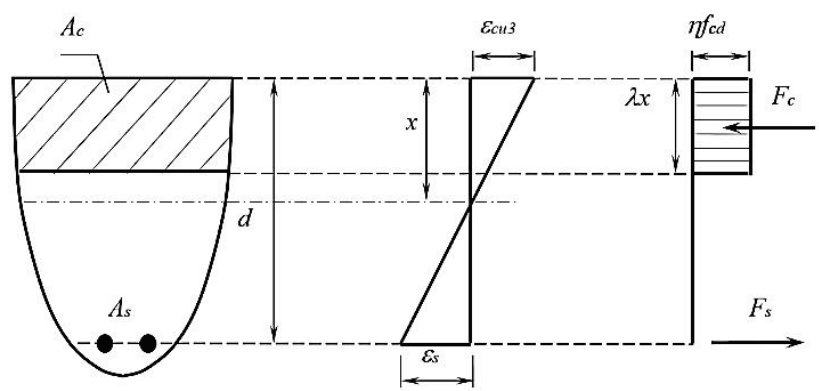

Figure 2 The uniform distribution of stresses in the compressed area. Coefficient that determines the designed height of the concrete compressed area is taken equal to $\lambda=0,8$, and factor taking into account the impact of various factors on the strength of concrete is recommended to take equal to $\eta=$ 1,0

$\frac{\sigma_{\mathrm{c}}}{f_{\mathrm{ck}, \mathrm{cd}}}=\frac{k \eta-\eta^{2}}{1+(k-2) \eta^{\prime}}$,

where:

$\eta=\frac{\varepsilon_{\mathrm{c}}}{\varepsilon_{\mathrm{cl}}}$

$\varepsilon_{\mathrm{cl}}-$ strain at maximum stresses in the calculation of the first group of limiting states accepted as $\varepsilon_{\mathrm{cl}, \mathrm{cd}}$, and according to the second group of limit states $-\varepsilon_{\mathrm{cl}, \mathrm{ck}}$. 
$k=1,05 E_{\mathrm{c}} \times \varepsilon_{\mathrm{cl}, \mathrm{cd}} / f_{\mathrm{cd}}$ and $k=1,05 E_{\mathrm{c}} \times \varepsilon_{\mathrm{cl}, \mathrm{ck}} / f_{\mathrm{ck}}$, prism respectively in the calculation by the first and second limit states; $E_{c}$ - initial modulus of deformation;

$$
\sigma_{\mathrm{c}}=f_{\mathrm{ck}, \mathrm{cd}} \sum_{k=1}^{5} a_{k} \eta^{k}
$$

where $a_{k}$ is polynomial coefficients determined using the parameters.

\subsection{The General Case of the Normal Section Calculation of Eccentrically Compressed Element}

Calculation of cross-sections of eccentrically compressed element in case of circular cross-section (Fig. 3 ) is made according to the following conditions:

$$
M \leq f_{\mathrm{cd}} S_{\mathrm{b}}-\sum \sigma_{\mathrm{s} i} S_{\mathrm{s} i}
$$

where: $M=N \cdot e-$ moment of longitudinal force $N$ with respect to an axis parallel to the line bounding the compressed area, and passing through the cross-section centre of the masses of most stretched or compressed bar of longitudinal reinforcement; $S_{\mathrm{b}}$ - static moment of cross-sectional area of the compressed concrete area relative to a respective specified axis; $S_{\mathrm{s} i}$ - static moment of the cross-sectional $i^{\text {th }}$ bar area of the longitudinal reinforcement relative to a respective specified axes; $\sigma_{\mathrm{s} i}$ stress in the $i^{\text {th }}$ bar of the longitudinal reinforcement, determined in accordance with the instructions of the relevant paragraph of the regulation.

The height of the compression area and the stress $\sigma_{\mathrm{s} i}$ determined by solving of equations system:

$$
\begin{gathered}
N=f_{\mathrm{cd}} A_{\mathrm{c}}-\sum \sigma_{\mathrm{si} i} A_{\mathrm{s} i} \\
\sigma_{\mathrm{s} i}=\frac{\sigma_{\mathrm{sc}, \mathrm{u}}}{1-\frac{\omega}{1,1}}\left(\frac{\omega}{\xi_{i}}-1\right) .
\end{gathered}
$$

Eq. (6) is empirical formula for finding the stresses in the reinforcing bars, where are: $\sigma_{\mathrm{sc}, \mathrm{u}}-$ ultimate stress in the reinforcement of the compressed area used for the construction of a heavy, fine and lightweight concrete, depending on the loads taken into account in the calculation; $\omega$ - characteristic of the compressed concrete area, defined by the expression $\omega=\alpha-0,008 f_{\text {cd }}$, where $\alpha$ - the coefficient that for heavy concrete is in interval 0.75 $\div 0.85 ; \zeta_{i}=x / h_{\mathrm{o} i}$, where is $h_{\mathrm{o} i}$-distance from an axis passing through the centroid of the cross-section of considered $i^{\text {th }}$ bar and parallel line that is bounding the compressed area and the furthest point of the compressed area (Fig. 3).

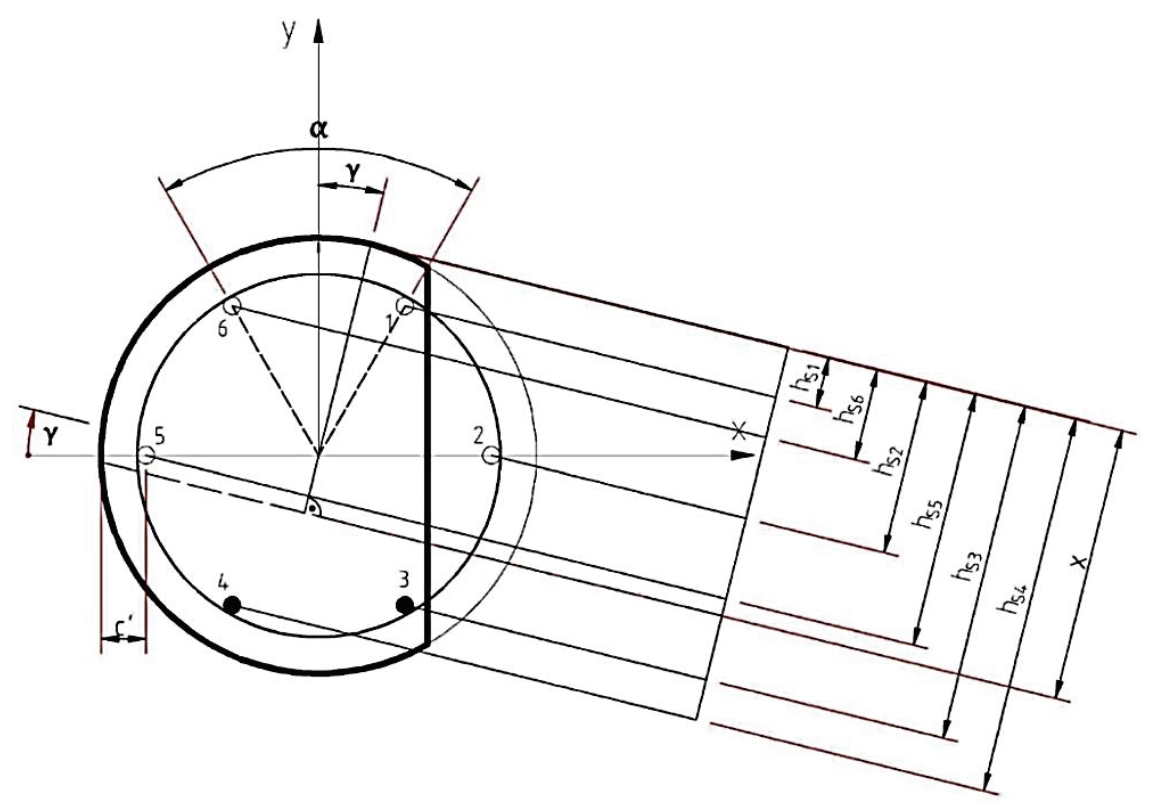

Figure 3 Scheme of the force and stresses in a cross-section normal to the longitudinal axis of the concrete element of circular cross-section, for calculation of the bearing capacity

Since these concrete columns are damaged during service, their calculation is treated as verification and, therefore, it is possible to use the simplified assumption of a uniform stress distribution by height of the compressed area. Thus, it is possible to formulate the basic assumptions of the calculation:

1) The hypothesis of plane sections is adapted, i.e., after deformation, cross-sections remain flat, but vary in linear dependence by the height of the deformation section.
2) Tensile strength of concrete is equal to zero; the forces in the tension area are fully carried by reinforcement bars.

3) The compressive strength of concrete is equal to $f_{\mathrm{cd}}$ and evenly distributed on the compressed concrete area.

4) Stresses in reinforcement bars are determined depending on the height of the compressed concrete area.

5) The tensile stresses in the reinforcement bars are taken less than the calculated tensile strength $f_{\mathrm{t}}$. 
6) The compressive stress in the reinforcement bars is taken less than the calculated resistance to compression $f_{\mathrm{yd}}$.

In the calculation process it is necessary to determine the unknown values of ultimate load $N$, the height of the compressed area $x$ and the stress in the reinforcement bars $\sigma_{\mathrm{si}}$.

In reviewing the case of eccentric compression additional condition was adopted. The condition states that the point of external force application, resultant of the compressive forces of the concrete and reinforcement bars and resultant forces in the tensile reinforcement must lie on the same straight line [14] p. 3.28 (Fig. 4). In this figure:

I-I - is a plane parallel to the plane of bending moment action, or a plane passing through the application points of the longitudinal force and the resultant of internal compressive and tensile forces;

B - the point of application of the resultant forces acting in the compressed reinforcement bars and in the concrete compression area.

\section{PARALLELISM CONDITION OF FORCE PLANES}

Due to the lack of data on key parameters that are necessary for finding bearing capacity of the element, it is necessary to define the conditions for finding fixed points, on which our system of equations will be based. The assumption for the calculation is that in case of sidewise eccentric compression it is required to comply with additional condition of the external and internal forces plain parallelism - the condition that the point of application of external force, resultant of the compressive forces of the concrete and reinforcement bars and resultant forces in the tensile reinforcement must lie on the same straight line (Fig. 4).

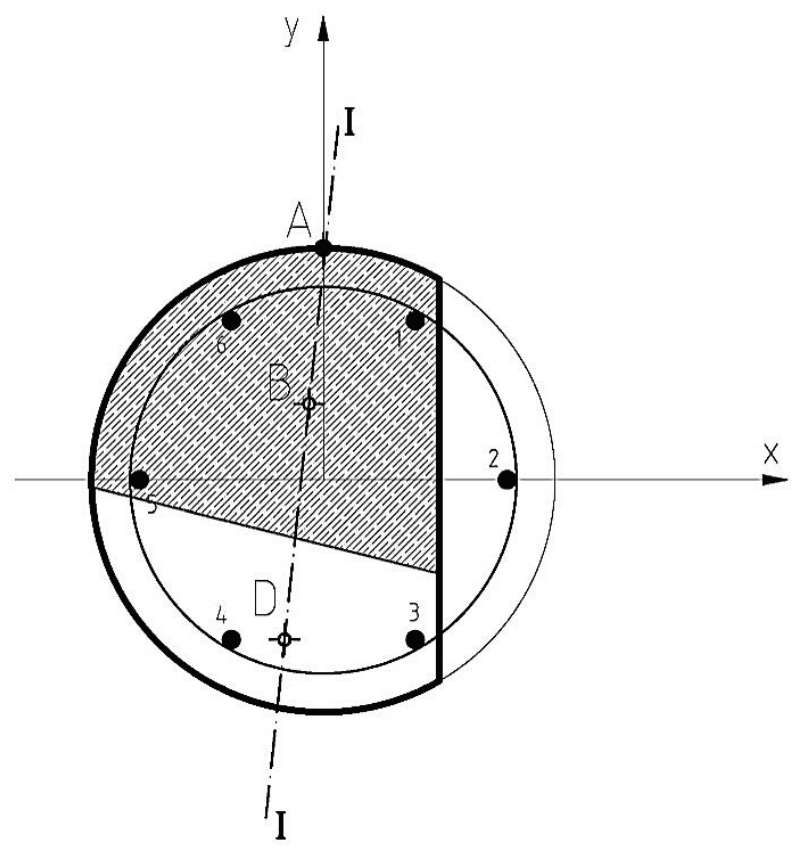

Figure 4 Force plane parallelism condition
To accurately determine the line I-I it is necessary to find (and fixate) the coordinates of points A, B and D, as follows:

- point A - the point of application of external force has known coordinates $\left(0, e_{y}\right)$;

- point B - resultant force of compressive stresses in the concrete $N_{\mathrm{c}}$ and reinforcement bars $N_{\mathrm{c}}$, it is denoted by the coordinates $\left(x_{b}, y_{b}\right)$;

- point D - and the point of application of the resultant forces in the tensile reinforcement bars, it is denoted by the coordinates $\left(x_{d}, y_{d}\right)$.

Since the points lie on the same straight line, then by finding the position of point $\mathrm{D}$ we can find position of point $\mathrm{B}$, and more importantly, applying the same rule, the position of the compression force resultant in the concrete i.e. the centroid of the compressed concrete area can be found.

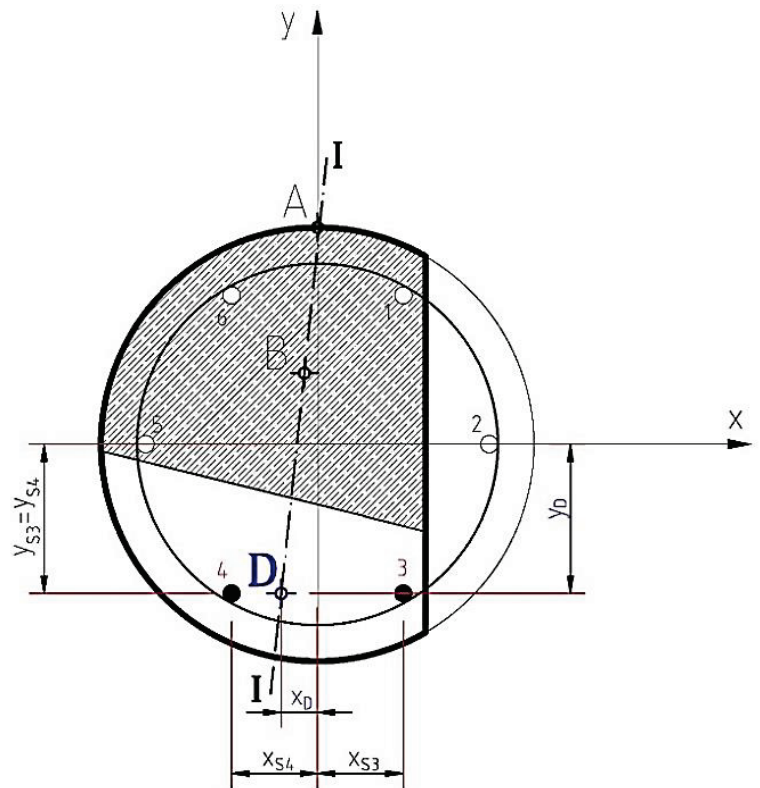

Figure 5 Determination of the coordinates of the resultant in the tension reinforcement bars

Let us consider Fig. 5. In the tensile area, stresses are carried by tensile reinforcement bars. Centroid of the tensile area (application point of resultant of the tensile stresses in the reinforcement bars) is located at the point D with the corresponding coordinates. In the reinforcing bars 3 and 4 acting forces $F_{\mathrm{s} 3}$ and $F_{\mathrm{s} 4}$ are:

$F_{\mathrm{s} 3}=\sigma_{\mathrm{s} 3} A_{\mathrm{s} 3}, \quad F_{\mathrm{s} 4}=\sigma_{\mathrm{s} 4} A_{\mathrm{s} 4}$

Obviously, $A_{\mathrm{s} 3}=A_{\mathrm{s} 4}=A_{\mathrm{s} n}=A_{\mathrm{s}}$ should be taken in the calculation due to the reinforcement of the entire crosssection with evenly distributed bars.

As stated previously, point $B$ is the point of application of resultant force of compressive stresses in the concrete and reinforcement bars:

$N_{\mathrm{R}}=N_{\mathrm{s}}^{\prime}+N_{\mathrm{c}}$

Force planes parallelism condition (Fig. 4) can also be applied to the compressed concrete area and then three main points $(\mathrm{C}, \mathrm{B}$ and $\mathrm{S})$ identified representing the 
resultant of individual ( $\mathrm{C}$ and $\mathrm{S}$ ), and joint action in the compressed area of the compressed element (Fig. 6).

The coordinates of the point $\mathrm{C}$ can be found knowing the position of the point $\mathrm{S}$, the coordinates of which we define using the conditions of the force moment equilibrium in the compressed reinforcement bars, relatively to the main axes:

$$
\begin{aligned}
& \sum M_{x}:\left(F_{\mathrm{S} 1}+F_{\mathrm{S} 2}+F_{\mathrm{S} 5}+F_{\mathrm{S} 6}\right) \cdot y_{\mathrm{S}}=\left(F_{\mathrm{S} 1}+F_{\mathrm{S} 6}\right) \cdot y_{1} \\
& y_{\mathrm{S}}=\frac{\left(F_{\mathrm{S} 1}+F_{\mathrm{S} 6}\right) \cdot y_{1}}{\left(F_{\mathrm{S} 1}+F_{\mathrm{S} 2}+F_{\mathrm{S} 5}+F_{\mathrm{S} 6}\right)}
\end{aligned}
$$

$$
\sum M_{y}:\left(F_{\mathrm{S} 1}+F_{\mathrm{S} 2}+F_{\mathrm{S} 5}+F_{\mathrm{S} 6}\right) \cdot x_{\mathrm{S}}=
$$$$
=\left(F_{\mathrm{S} 1}-F_{\mathrm{S} 6}\right) \cdot x_{1}+\left(F_{\mathrm{S} 2}-F_{\mathrm{S} 5}\right) \cdot x_{2}
$$

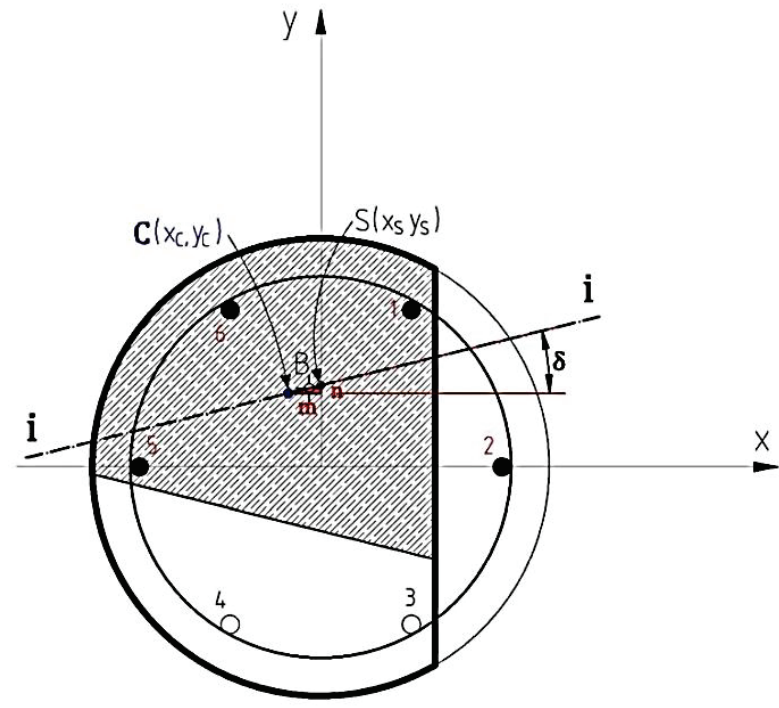

$x$

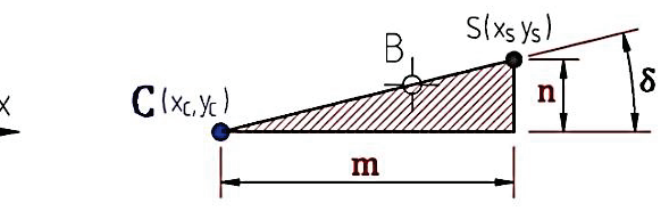

Having considered the triangle, now it is necessary to determine the position of point $\mathrm{C}$ coordinates using the known coordinates of the point $\mathrm{S}$ :

$$
\begin{aligned}
& x_{\mathrm{C}}=x_{\mathrm{S}}-m \\
& y_{\mathrm{C}}=y_{\mathrm{S}}-n
\end{aligned}
$$

The value of side $n$ can be found by tangent $\delta$ :

$n=m \cdot \tan \delta$

The final value of the centroid coordinates of the compressed concrete area are:

$$
\begin{aligned}
& x_{\mathrm{C}}=x_{\mathrm{S}}-m \\
& y_{\mathrm{C}}=y_{\mathrm{S}}-m \cdot \tan \delta
\end{aligned}
$$

$$
\begin{aligned}
& x_{\mathrm{C}}=\frac{\left(F_{\mathrm{S} 1}-F_{\mathrm{S} 6}\right) \cdot x_{1}+\left(F_{\mathrm{S} 2}-F_{\mathrm{S} 5}\right) \cdot x_{2}}{\left(F_{\mathrm{S} 1}+F_{\mathrm{S} 2}+F_{\mathrm{S} 5}+F_{\mathrm{S} 6}\right)}-m \\
& y_{\mathrm{C}}=\frac{\left(F_{\mathrm{S} 1}+F_{\mathrm{S} 6}\right) \cdot y_{1}}{\left(F_{\mathrm{S} 1}+F_{\mathrm{S} 2}+F_{\mathrm{S} 5}+F_{\mathrm{S} 6}\right)}-m \cdot \tan \delta
\end{aligned}
$$

In view of $(11,12)$ can be written:

$$
x_{\mathrm{S}}=\frac{\left(F_{\mathrm{S} 1}-F_{\mathrm{S} 6}\right) \cdot x_{1}+\left(F_{\mathrm{S} 2}-F_{\mathrm{S} 5}\right) \cdot x_{2}}{\left(F_{\mathrm{S} 1}+F_{\mathrm{S} 2}+F_{\mathrm{S} 5}+F_{\mathrm{S} 6}\right)} .
$$

When the coordinates of the centroid of compressed reinforcement bars are determined, it is possible to determine the exact coordinates of the centroid of the compressed concrete resultant via line i-i, i.e. point $\mathrm{C}$. As shown in Fig. 6, line $\mathrm{i}-\mathrm{i}$ (on which are located the centroids of all internal forces in the compressed concrete area) is located at an angle $\delta$ to the horizontal axis. Let us construct a right-angled triangle, whose hypotenuse is a direct part of the line $\mathrm{i}-\mathrm{i}$, and the sides of the triangle are parallel to the main axis system with endpoints $\mathrm{C}$ and $\mathrm{S}$. The length of the part is defined as $m$ and $n$.
After locating and identifying the centroid coordinates described by a straight line I-I, unknown values can be determined based on which a system of equations will be set-up to determine the bearing capacity of the damaged element with a circular cross-section. It should be noted that the forces in the bars in the tension zone $\left(F_{\mathrm{S} 3}\right.$ and $\left.F_{\mathrm{S} 4}\right)$ are calculated with the appropriate working height $h_{\mathrm{S} 3}$ and $h_{\mathrm{S} 4}$ (the distance from the axis passing through the centroid of cross-section centre of the considered bar and parallel line that is bounding compressed area to the most distant point of the compressed-sectional area ). For this reason, it is not necessary to calculate the coordinates of point $\mathrm{D}$, but each bar in the system of equations will be calculated with its own specific height $h_{\mathrm{o} i}$.

Thus, if the expression for the necessary unknown variables is found, a system of equations can be set-up. The required variables are:

1) $N$ - bearing capacity of column;

2) $x$ - height of the cross-section compressed area;

3) $\gamma$-inclination angle of the neutral line;

4) $\delta$-inclination angle of the line passing through the points of compressed concrete area and compressed reinforcement resultant;

5) $m$ - unknown triangle side. 
The last two values are needed to determine the position of the centroid of the compressed concrete area (13). Due to the two additional unknown variables, two additional equations must be added in order to obtain a system $5 \times 5$ (five equations with five unknowns), and thus, find the bearing capacity of cross-section. Five equilibrium equations are:

I. The equilibrium equation of forces:

$$
N-f_{\mathrm{cd}} \cdot A_{\mathrm{c}}+\sum \sigma_{1-6} \cdot A_{\mathrm{s}}=0
$$

II. The moments equilibrium with respect to the $x$ axis:

$$
\begin{aligned}
& N \cdot e-f_{\mathrm{cd}} \cdot A_{\mathrm{c}} \cdot y_{\mathrm{C}}-\left(\sigma_{1}+\sigma_{6}\right) \cdot A_{\mathrm{s}} \cdot y_{1}+ \\
& +\left(\sigma_{3}+\sigma_{4}\right) \cdot A_{\mathrm{s}} \cdot y_{3}=0 .
\end{aligned}
$$

III. The moments equilibrium with respect to the $y$ axis:

$$
\begin{aligned}
& \left(\sigma_{3}-\sigma_{4}\right) A_{\mathrm{s}} \cdot y_{\mathrm{S} 3}-\sigma_{1} \cdot A_{\mathrm{S}} \cdot x_{\mathrm{S} 1}-\sigma_{2} \cdot A_{\mathrm{s}} \cdot x_{\mathrm{S} 2}+ \\
& +\sigma_{5} \cdot A_{\mathrm{s}} \cdot x_{\mathrm{S} 5}+\sigma_{6} \cdot A_{\mathrm{S}} \cdot x_{\mathrm{S} 6}-f_{\mathrm{cd}} \cdot A_{\mathrm{c}} \cdot x_{\mathrm{C}}=0 .
\end{aligned}
$$

IV. The static moment of the compressed concrete area with respect to the $x$ axis:

$$
S_{x^{\prime}}=A_{1} y_{1}-A_{2} y_{2}
$$

V. The static moment of the compressed concrete area with respect to the y axis:

$S_{y^{\prime}}=A_{1} x_{1}-A_{2} x_{2}$

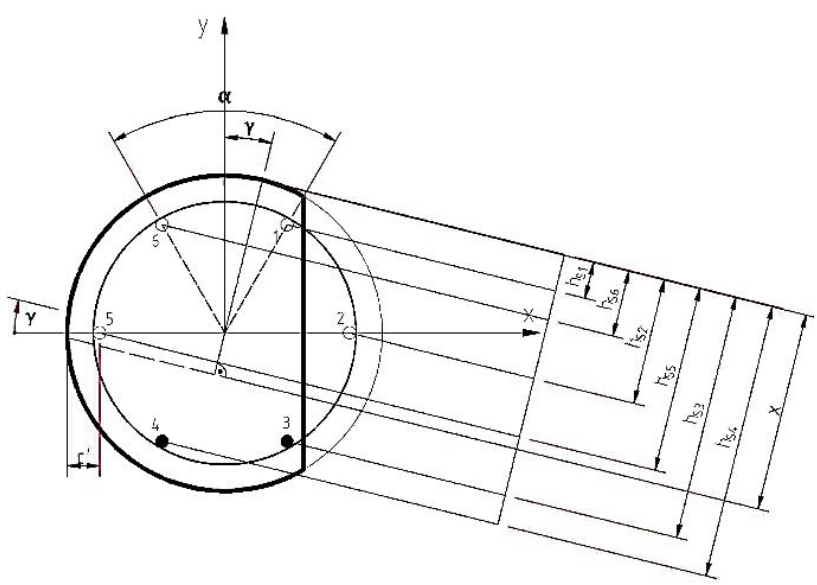

Figure 7 Scheme of the main geometric variables for the general case of the calculation of damaged compressed element with circular cross-section

In Eqs. $(14) \div(18)$ stresses in reinforcement bars are determined by (3). In this formula, the unknown is the value of compression area height $\xi_{i}=x / h_{\mathrm{o} i}$, where $h_{\mathrm{o} i}-$ is the distance from the axis which passes through the centroid of the cross-section $i^{\text {th }}$ considered bar and parallel line that bounds the compressed area and the furthest point of the cross-section compressed area. Determination of the $h_{\mathrm{o} i}$ value is possible by crosssectional geometry. $h_{\mathrm{s} i}$ values in this case will depend on the type (depth) of the column damage. Below is shown the case of working height $h_{\mathrm{s} i}$ determination, which depends on the depth of column damage. The example shows the case where damage of the element is $b=R / 2$, where $R$ - radius of the circular cross-section. Some differences may be noted in the determination of the working height that is generally related by the depth of the damage and the inclination of the neutral axis $\gamma$.

Fig. 7 shows the ratio of $h_{\mathrm{o} i}$ size for each bar and main parameters, that are necessary to obtain length of $h_{\mathrm{o} i}$. It is important to note that the length must be obtained from already known values, including basic unknowns defined by system of equations.

Fig. 8 shows the internal relations which determine $h_{\mathrm{s} 1}$ value:

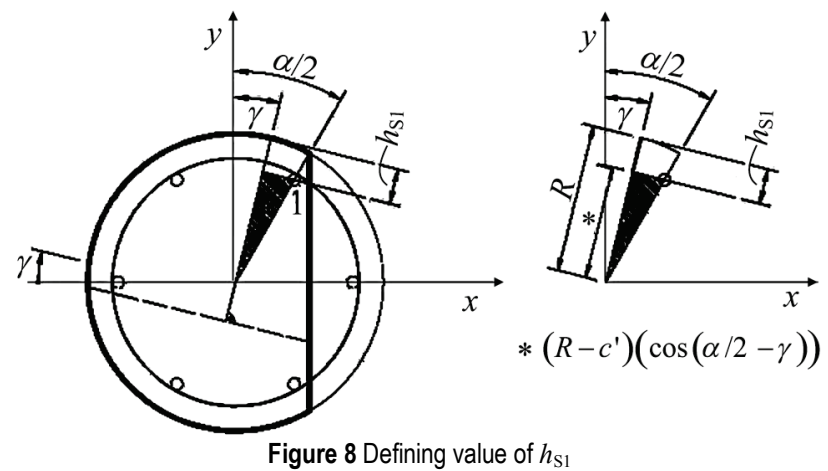

Expression to determine $h_{\mathrm{S} 1}$ is:

$h_{\mathrm{S} 1}=R-\left[\left(R-c^{\prime}\right)(\cos (\alpha / 2-\gamma))\right]$

where $c^{\prime}$ is distance from the cross-section centroid of the $i^{\text {th }}$ considered bar to concrete outer edge. Thus, the working height of cross-section for each bar is defined.

Thus, the expression for the working height $h_{\mathrm{S}}$ for each bar, in the boundary conditions of damaged elements is determined.

Static moments in Eqs. (19) and (20) are determined based on the geometry of the cross-section and the parameters of damage by dividing the section on "simple" shapes (Fig. 9).

Calculation of the "simple" shapes area with respect to $x^{\prime}$ and $y^{\prime}$ axis represents a special problem because of their geometric complexity. These elements should be divided into simple basic geometric shapes, so the calculation of the area will be possible by the standard analytical methods. In this sense, it is necessary to introduce new variables for the calculation purpose, but also it cannot lead to new unknown, however, it is necessary to express all of them by known variables (including the unknown variables of base equation system). Thus, the entire compressed area is divided into basic geometric shapes with corresponding sizes, which are necessary for the calculation of entire area (Fig. 10).

As shown in Fig. 10, the compressed area is divided into circular sector and two triangles. These areas will be expressed in terms of the basic expression for the areas of geometric shapes. The basic values for calculation (sides and angles) come with newly introduced values, which were obtained from the previously known variables and values (which contain basic unknown variables $x$ and $\gamma$ ). 


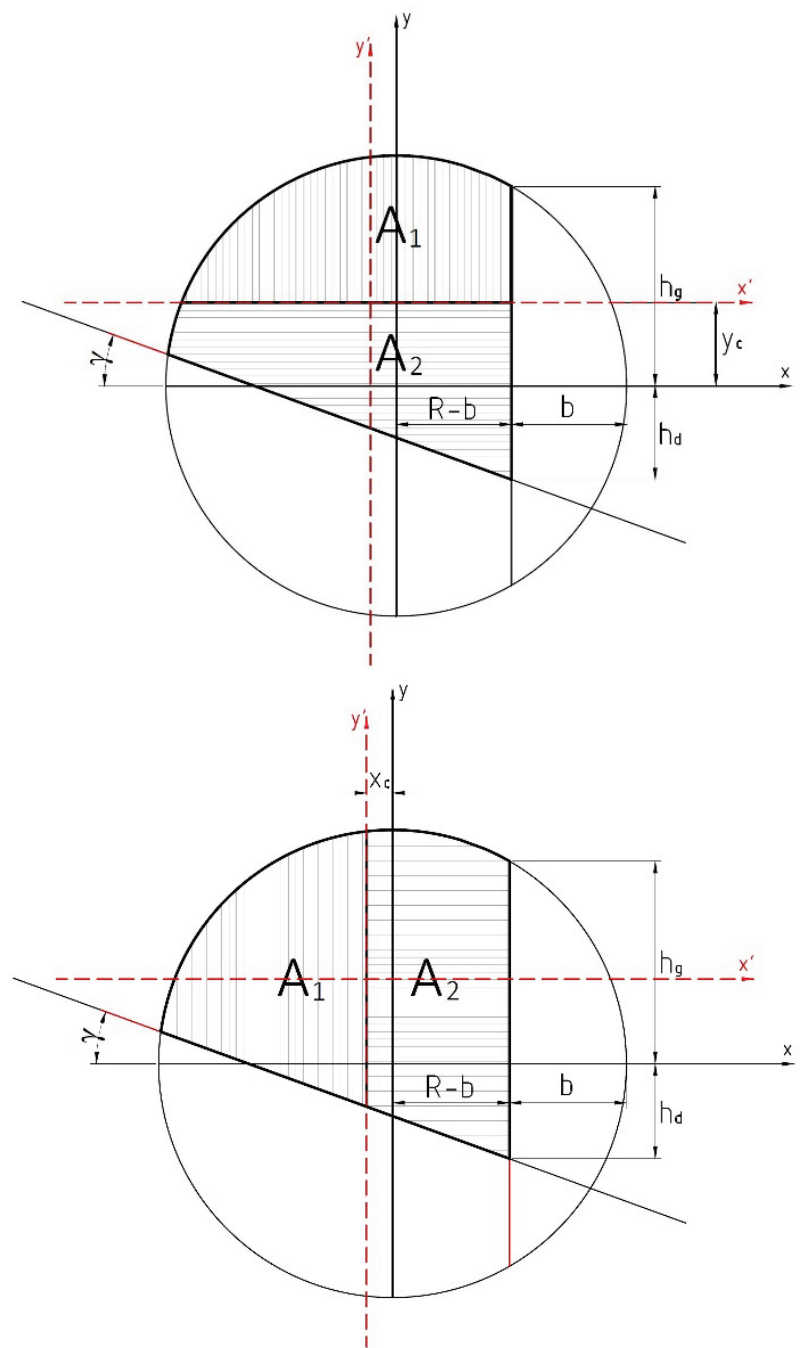

Figure 9 Determination of the static moments of the compressed concrete area: upper circle: with respect to $x^{\prime}$ axis; lower circle: with respect to $y^{\prime}$ axis

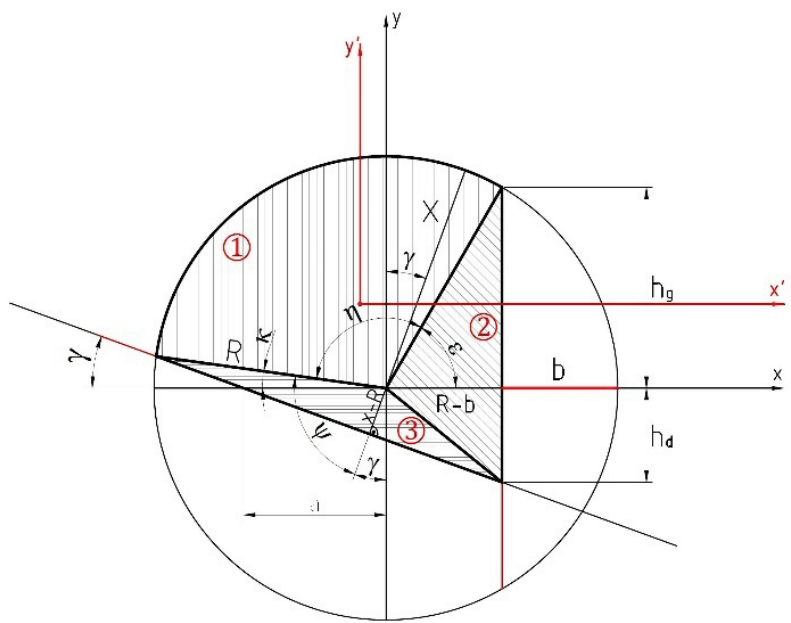

Figure 10 The compressed area is divided into simple geometric shapes with corresponding dimensions

Required variables are obtained in the following form:

$$
\begin{aligned}
& \varepsilon=\arccos \left(1-\frac{b}{R}\right), \\
& \psi=\arccos \left(\frac{x}{R}-1\right),
\end{aligned}
$$
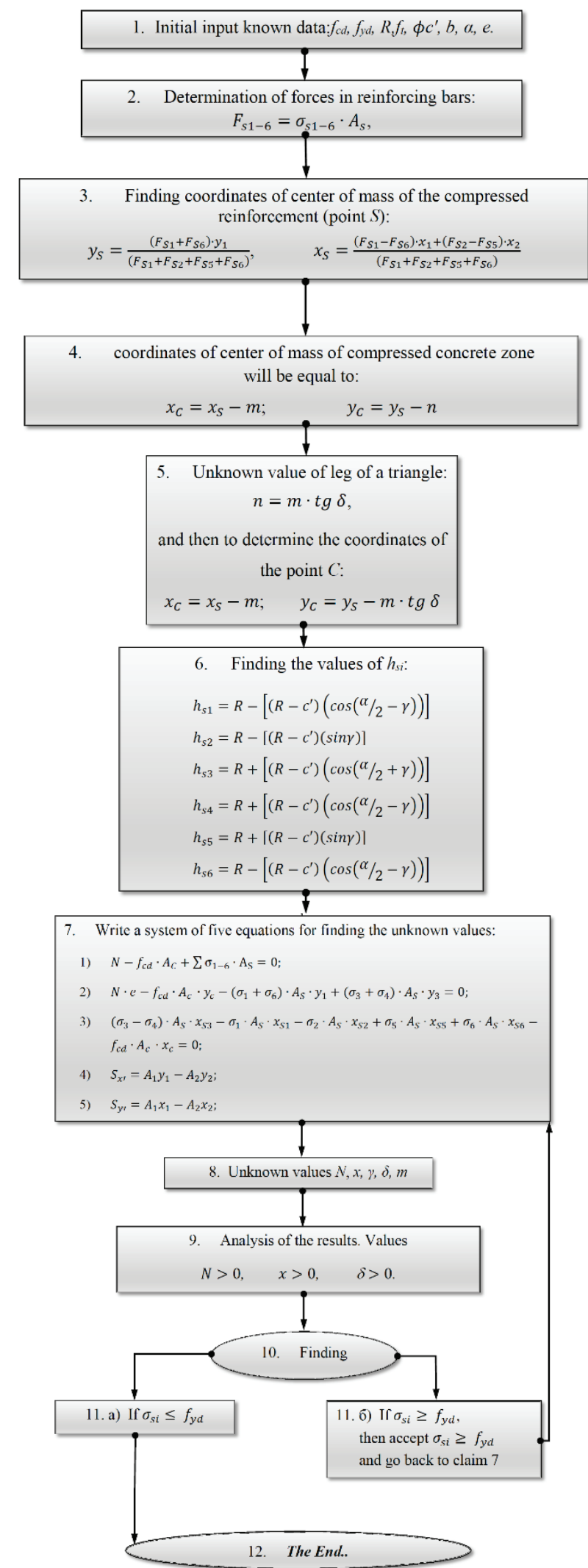

Figure 11 Flow-chart of the calculation process

$$
\begin{aligned}
& \eta=\frac{3 \pi}{2}-\varepsilon-\psi-\gamma, \\
& a=\frac{x-R}{\sin \gamma}, \\
& h_{\mathrm{g}}=\sqrt{b(2 R-b)},
\end{aligned}
$$


$h_{\mathrm{d}}=\left(\frac{x-R}{\sin \gamma}-b+R\right) \tan \gamma$.

Using these expressions, an expression for determining the area of a triangle and a circle sector was obtained, thus completing the description of the compressed concrete area.

$$
\begin{aligned}
& A_{1}=\frac{1}{2} \cdot \eta \cdot R^{2} \\
& A_{2}=\frac{1}{2}\left(h_{\mathrm{g}}+h_{\mathrm{d}}\right)(R-b) \\
& A_{3}=\frac{1}{2} \cdot a\left[R \cdot \sin \left(\psi+\gamma-\frac{\pi}{2}\right)+h_{\mathrm{d}}\right]
\end{aligned}
$$

The final area is obtained by summing the areas of three separate constituent areas: $A=A_{1}+A_{2}+A_{3}$.

Thus, everything needed to solve the system of Eqs. $(14) \div(18)$ is obtained, and now it is possible to get the values of the five unknown variables. Knowing the height of the compressed area $x$ the value of stresses acting in reinforcing bars using formula (6) can be determined.

Now, flow-chart of the complete calculation can be given in Fig. 11.

\section{CONCLUSION}

The calculation is developed following which it is possible to find the unknown quantities of the studied problem. Method of calculation is developed on the basis of parallelism condition of force planes. End result of the calculation is the damaged element's bearing capacity. It is important to correctly identify problem task, primarily due to the geometric complexity of the compressed zone.

By today's standards there is yet no basic algorithm for the calculation of damaged rc elements. This calculation method is a good starting point for further analysis in different types of damage.

\section{REFERENCES}

[1] Bresler, B. (1960). Design Criteria for Reinforced Concrete Columns under Axial Load and Biaxial Bending. $A C I$ Journal, Proceedings, 57(5), 481-490.

[2] Fekete, G. (1973). Ultimate Strength Design of Circular Reinforced Concrete Cross-Sections. Civil EngineeringASCE, 43(II), 80-81.

[3] Ultimate Load Tables for Circular Columns, Portland Cement Association, Skokie, 1960, 30 pp.

[4] CRSI Handbook Based Upon the 1983 AC1 Building Code, Concrete Reinforcing Steel Institute, Schaumburg, 1984 pp. 4-1 to $4-101$

[5] ACI Committee 340, Design Handbook in Accordance with the Strength Design Method of ACI318-83: V. 2-Columns, SP-17A(85), American Concrete Institute, Detroit, 1985, $222 \mathrm{pp}$.

[6] Klimenko, E. V. (2010). Technical condition of buildings and structures / Klimenko E. V. - Odesa: OGASA, 284 p.

[7] Klimenko, E. V. (2008). Control of the technical condition of steel-concrete structures / Klimenko E. V., Koval O. V., Building constructions: A collection of scientific works - K.: NDIBK, 70, 151-157.
[8] Klimenko, E. V. (2004). Deformability and technical condition of bearing structures of the Vorskla stadium in Poltava / Klimenko E. V., Pogrinij V. V., Dovzhenko O. O., Building constructions: a collection of scientific works - K.: NDIBK, 55, 319-324.

[9] Klimenko E. V. (2005). On the issue of reliability of reinforced concrete structures / Klimenko E. V., Building constructions: a collection of scientific works - K.: NDIBK, 2, 210-215.

[10] Klimenko, E. V. (2003). On the issue of prediction of technical condition of reinforced concrete structures / Klimenko E. V., Building constructions: a collection of scientific works - K.: NDIBK, 59(2), 68-73.

[11] Zavoloka, Yu. B. (2000). Assessment of technical condition and reinforcement of reinforced concrete structures / Zavoloka Yu. B., Kobrinec V. M., Zavoloka M. V., Odessa: City of Masters, $292 \mathrm{p}$.

[12] Matveev, E. P. (1998). Technical solutions for strengthening and heat insulation of houses and public buildings / Matveev E. P., Meshechkin V.V., M: Old Basmannaya, $209 \mathrm{p}$.

[13] BS EN 1992-1-1:2004 - Design of concrete structures. General rules and rules for buildings, The European Union Per Regulation 305/2011, Directive 98/34/EC, Directive 2004/18/EC

[14] Concrete and reinforced concrete structures (II-a): DBN B.2.6.-2011. - (Effective from 2011-06-01), 2009, 101 p. (State Building Regulations of Ukraine).

\section{Contact information:}

Matija OREŠKOVIĆ, PhD, Eng. Sci.

University North

104. brigade 3 , Varazdin, Croatia

moreskovic@unin.hr

Dr. sc. levgenii KLYMENKO, Professor

Odessa State Academy of Civil Engineering and Architecture

Ul. Didrihsona 4, Odesa 65029, Ukrajina,

klimenkoew57@gmail.com

\section{Aleksej ANISKIN, Mag. Ing. Geoing.}

University North

104. brigade 3, Varazdin, Croatia

aaniskin@unin.hr

Dr. sc. Goran KOZINA, Associate Professor

University North

104. brigade 3 , Varazdin, Croatia

gkozina@unin.hr 